\title{
Analysis of Potential Regional Mapping of Regional Specialization and Use of Technology in the Stimulus of Export Value
}

\author{
Dede Yoga Paramartha \\ Statistics \\ Polytechnic of Statistics STIS \\ Jakarta, Indonesia \\ 15.8557@stis.ac.id
}

\author{
Anisa Muna Majidah \\ Statistics \\ Polytechnic of Statistics STIS \\ Jakarta, Indonesia \\ 15.8512@stis.ac.id
}

\begin{abstract}
The era of the industrial revolution requires extra handling if you want to compete well in it. In focusing on determining the right policy, it certainly requires an indicator that is able to answer the needs of my policy. The need that the Indonesian government usually wants is spatial mapping, given that Indonesia has a high heterogeneous level. In entering the era of industrial revolution, the role of technology is certainly undeniable, thus it is necessary to have indicators to illustrate how ready Indonesia is to navigate the waves of technology. The strategy that can be combined with technological progress is the diversity of Indonesia itself. With the optimization of specialization and regional comparative advantage can trigger synergies that can be used as a basis in competing in the international trade market. Therefore, there needs to be an analysis of the effects of technology combined with specialization as the proxy for regional comparative advantage of Indonesia. This can help in analyzing productivity or even other trading problems. Guided by the establishment of a competitiveness index and by utilizing spatial panel data modeling, this study is able to map the direct and indirect effects of these variables on an area. On the other hand, it can be seen how indicators improve competitiveness and not just trading volume.
\end{abstract}

Keywords-Comparative Technology, Spatial Analysis

Advantage, Specialization,

\section{INTRODUCTION}

Export is one way to increase revenue in Indonesia. The weak exchange rate causes the export value received to be high. In addition, international trade is also a solution to providing income or establishing good bilateral cooperation with other countries.

Indonesia's international trade is currently fighting the Challenge of the 4.0 Industrial Revolution. In addition, the higher the effect of globalization makes Indonesia also difficult to compete for domestically. According to data from the Central Statistics Agency (BPS), moving Indonesia's trade reduced the deficit quite badly. In fact, discussed in 2013 until 2014 spent twin-deficit.

This is certainly not a good thing, considering economic growth in 2011. It is necessary to help and improve the right target to fix investment specifically in the export sector. The current export sector is very promising because the added value generated by local products will result in higher trade yields in countries with strong exchange rates. But the problem now is Indonesia's inability to use information technology. According to the World Economic Forum, Indonesia's technology adoption value reached 61 points, but what was unfortunate was that the value of innovation was only 38 points. This shows how technology cannot change either as a driver of export value.

Another alternative that can be done is to use, so that there will be a more focused technology transfer. Focused use of technology will be made. In addition, the inter-island heterogeneity of Indonesia will bring up spatial analysis so that the government can see more intense patterns of agglomeration and distribution so that it becomes a suggestion in making policies based on another perspective.

Therefore, this paper was created in order to examine how the role of specialization and technological effects in improving export performance. Aside from being a literature review in subsequent studies that are better, this research is also expected to be able to capture the phenomenon that is happening in Indonesia today regarding exports. Thus, this research can also be used as a means of recommendations in determining policy.

\section{METHODOLOGY}

\section{A. Theory}

Exports can be influenced by labor productivity, as well as investment in human capital. Productivity will be able to increase the volume of exports, while investment in human capital will result in long-term growth. Arnold and Hussinger (2005) analyzed the relationship between firm productivity and export behavior in German manufacturing firms by using a total factor productivity approach; they found that highly productive firms were self-selected for export market entries, while exporting it did not play a significant role in productivity improvements. In increasing productivity, specialization efforts can be one alternative that can be done. Specialization can foster innovation from companies that have a good effect on labor market performance (Martin Robson, 2006). Innovation that occurs, can be a stimulus for productivity.

\section{1) Moran's I}

Moran (1950) first proposed test statistics to assess the level of spatial autocorrelation between adjacent locations. To compile this statistic for $\mathrm{n}$ independent variables $X_{i}(\mathrm{i}=$ 
$1, \ldots, \mathrm{n})$ at the lattice location $\left\{s_{i}: \mathrm{i}=1, \ldots, \mathrm{n}\right\}$ in the formulation $\delta_{i j}$ is defined as an indicator such that $\delta_{i j}=1$ if $i-$ th location and $\mathrm{j}$-th next to each other, and $\delta_{\mathrm{ij}}=0$ otherwise. But over time $\delta_{\mathrm{ij}}$ can be defined as weighting closeness by Anselin (2008), with a range of values from zero to 1 based on how closely the relationship between locations. Assuming that observations have constant means, the obvious way to derive is to define $Z_{i}=X_{i}-\bar{X}_{\text {. }} \mathrm{i}=1, \ldots$, n. Initially (Moran, 1950), Moran's test statistics were defined as follows.

$$
I^{0}=\frac{\sum_{i=1}^{n} \sum_{j=1}^{n} \delta_{i j} z_{i} z_{j}}{\sum_{i=1}^{n} z_{i}^{2}}
$$

\section{2) CARS (Coefficient of Absolute Regional Specialization)}

CARS is an absolute index of specialization in regional work. This is calculated as the coefficient of variation in employment in each industry. Higher CARS values indicate an increase in the spread of employment in all industries and hence an increasing level of specialization.

$$
\text { CARS (Spesialisasi Absolut) }=\frac{\left[\sum_{i=1}^{n} \frac{x_{i}-\bar{x}_{1}}{n-1}\right]^{\frac{1}{2}}}{x_{i}}
$$

\section{B. Model and Statistical Tools}

This research was conducted in 33 provinces in Indonesia with research years in 2015 and 2016. The variables of this study were the value of exports, specialization, skills in the use of technology, and the interaction between access and skills in the use of technology.

In this study using the method of spatial regression analysis. The use of spatial regression is to see the effect of the influence of specialization variables, skills in the use of technology, and the interaction of access and skills on export values in terms of the spatial effects that occur. The use of this method is based on the theory from previous research which says that aspects of the export of an area can be influenced by the surrounding area due to raw material requirements. In addition, there are also spatial possibilities from aspects of regional specialization and technology that cause residuals to have spatial effects.

Spatial model specifications consist of:

- $\quad$ Spatial lag model

$$
\begin{aligned}
& \text { Export }_{i}=\beta_{0}+\beta_{1} \text { Specialization }_{i}+\beta_{2} \text { Skill }_{i}+
\end{aligned}
$$

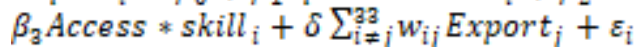

- Spatial error model

$$
\begin{aligned}
& \text { Export }_{i}=\beta_{0}+\beta_{1} \text { Specialization }_{i}+\beta_{2} \text { Skill }_{i}+ \\
& \beta_{1} \text { Access } * \text { skill }_{i}+\lambda \sum_{i \neq i}^{a d} w_{i j} u_{i}+\varepsilon_{i}
\end{aligned}
$$

With spatial weighting economic gravity with economic force which is proxied by the value of GRDP on the basis of neighbouring regional constant prices, and dividing it by the distance of each region based on the coordinates of the center of the province. The model specifications chosen for 2015 and 2016 are adjusted for the spatial dependencies that occur.

\section{RESULT AND DISCUSSION}

\section{A. Spatial Autocorrelation}

Before conducting spatial modeling as a concern in this study, it is necessary to have spatial indications generated from the model. In modeling, the residual models of 2015 and 2016 were tested with multiple linear regression. Then the resulting residuals are tested with Moran's I. statistics

TABLE I. MORAN I OF INDONESIA'S EXPORT VALUE IN 2015 - 2016

\begin{tabular}{|c|c|c|c|c|}
\hline Year & Moran I & E(I) & Var(I) & p-value \\
\hline 2015 & -0.3116 & -0.0410 & 0.0070 & 0.0012 \\
\hline 2016 & -0.3514 & -0.0433 & 0.0068 & 0.0002 \\
\hline
\end{tabular}

The Moran I index is used to prove the spatial effect of export values in the provinces in Indonesia in 2015 and 2016. The Moran I index in 2015 and 2016 showed significant results at $\alpha=5 \%$, so it can be concluded that there are spatial autocorrelations between provinces in Indonesia, with autocorrelation negative spatial which means the effects are increasingly spreading from 2015 to 2016. In addition, there are indications of a backwash effect due to the negative value of this moran'I index. In other words, spatial linkages produce negative effects on the surrounding area. This gave rise to domestic competition. And another bad thing is the increasingly negative moran'I index value.

In addition, the economic weighting used means that the regional economic values of each region will be able to influence each other's export values in each region.

\section{B. Spatial Regression Model}

The steps in spatial regression analysis begin by detecting whether there are spatial dependencies that occur. Statistical testing using the Lagrange Multiplier (LM) test was conducted to test the effects of spatial lag and spatial errors. The test results obtained are as follows.

TABLE II. SPATIAL DEPENDENCIES TEST

\begin{tabular}{|c|l|c|c|c|}
\hline Year & \multicolumn{1}{|c|}{ LM test } & LM-stat & df & p-value \\
\hline \multirow{4}{*}{2015} & LM lag & 5.9215 & 1 & 0.0150 \\
\cline { 2 - 5 } & LM error & 8.2790 & 1 & 0.0040 \\
\cline { 2 - 5 } & Robust LM lag & 1.1466 & 1 & 0.2843 \\
\cline { 2 - 5 } & Robust LM error & 3.5042 & 1 & 0.0612 \\
\cline { 2 - 5 } & SARMA & 9.4257 & 2 & 0.0090 \\
\hline \multirow{4}{*}{2016} & LM lag & 7.3423 & 1 & 0.0067 \\
\cline { 2 - 5 } & LM error & 10.5210 & 1 & 0.0012 \\
\cline { 2 - 5 } & Robust LM lag & 1.0853 & 1 & 0.2975 \\
\cline { 2 - 5 } & Robust LM error & 4.2642 & 1 & 0.0389 \\
\cline { 2 - 5 } & SARMA & 11.6060 & 2 & 0.0030 \\
\hline
\end{tabular}

Before forming a regression model, first determining the spatial dependencies that occur. Based on the spatial 
dependencies, spatial lag and spatial errors can be used both in 2015 and 2016. However, there are spatial autocorrelations so that the spatial autoregressive model is better used. This is based on spatial lag statistics which are able to have more statistical and economic meaning and econometrics.

After obtaining the appropriate spatial dependencies, multiple linear regression modeling is then performed. The modeling results for 2015 and 2016 are as follows.

TABLE III. MODEL ESTIMATION RESULT IN 2015

\begin{tabular}{|l|c|c|c|c|}
\hline \multicolumn{1}{|c|}{ Variable } & Coefficient & Std. Error & z-value & p-value \\
\hline Intercept & 331.9403 & 176.1354 & 1.8846 & 0.0595 \\
\hline Spatial lag & -0.3129 & 0.1409 & -2.2207 & 0.0264 \\
\hline Specialization & 168.5766 & 73.1121 & 2.3057 & 0.0211 \\
\hline Skill & -107.2703 & 32.2942 & -3.3217 & 0.0009 \\
\hline Access*skill & 11.0034 & 1.7841 & 6.1674 & $6.94 \times 10^{-10}$ \\
\hline
\end{tabular}

The value of specialization has a significant positive effect. However, the problem is the negative effects of the use of technology skills that also significantly affect the value of exports. This is certainly an indication that the use of technology in Indonesia is still not on target.

TABLE IV. MODEL ESTIMATION RESUlT IN 2016

\begin{tabular}{|l|c|c|c|c|}
\hline \multicolumn{1}{|c|}{ Variable } & Coefficient & Std. Error & z-value & p-value \\
\hline Intercept & 298.7880 & 185.4675 & 1.6110 & 0.1072 \\
\hline Spatial lag & -0.3398 & 0.1486 & -2.2872 & 0.0222 \\
\hline Specialization & 181.4813 & 78.9874 & 2.2976 & 0.0216 \\
\hline Skill & -94.4576 & 33.1399 & -2.8503 & 0.0044 \\
\hline Access*skill & 9.5791 & 1.9349 & 4.9507 & $7.39 \times 10^{-7}$ \\
\hline
\end{tabular}

In 20016 similar things also happened, but it was seen that the effects of specialization were increasing and also the effects of skills in using technology experienced positive changes. Another changing effect is the higher negative spatial effects that occur.

Based on the tabulation of estimation results, in terms of index specialization has the effect of increasing the export value of 168 billion rupiah in 2015 and 298 billion rupiah in 2016 if there is a $1 \%$ increase in specialization. This indicates that from 2015 to 2016, the influence of specialization has increased. These results indicate good potential where the effect of specialization will be increasingly felt towards increasing the value of exports each year.

In terms of skill, it appears that skills in the use of technology have a negative influence on the value of exports both in 2015 and 2016. In 2015 the effect of the skill variable was -107.27 which means that there would be a decline in the value of exports of 107.27 billion rupiah if this skill index would increase by $1 \%$. While in 2016, the effect of the skill variable will be -94.46 . This is contrary to the theory that there should be an increase in technology when there is an increase in the value of exports. This is indicated by the low access to technology, so that the use of skills is not optimal.
From 2015 to 2016 there was a decrease in the negative effects of skills in the use of technology on the value of exports. This shows the provision of access that has begun to become qualified so that it is finally able to increase the value of exports. This result is indicated by the interaction between access and skills that have a positive influence on the value of exports. From the chain effects produced, the effects of access began to decline because of the optimism of technology.

Spatial lag has a negative and significant effect on the value of exports. Significant coefficients indicate a linkage between the value of exports between regions, meaning that the export value of a region other than determined by independent variables is also influenced by the export value of the surrounding area. The influence exerted in 2015 was 0.31 and in 2016 it was -0.34 . This means that an area will be affected by the area around it by the coefficient value when the neighboring area has an increase in the value of exports on average by 1 billion.

With the formation of lag effects on the spatial model that has been created, direct and indirect effects can be made. Direct effects are effects that occur due to variables in the province itself, whereas indirect effects are effects of variables in other provinces which have spatial interrelationships. Of the two effects, the total effect that will be felt by a province that has spatial relations with other provinces will be formed. The measurement results for each effect are as follows.

TABLE V. IMPACT MEASURES IN 2015

\begin{tabular}{|l|c|c|c|}
\hline \multicolumn{1}{|c|}{ Variable } & Direct & Indirect & Total \\
\hline Specialization & 170.8994 & -42.4964 & 128.4030 \\
\hline Skill & -108.7484 & 27.0417 & -81.7066 \\
\hline Access*skill & 11.1550 & -2.7738 & 8.3812 \\
\hline
\end{tabular}

TABLE VI. IMPACT MEASURES IN 2016

\begin{tabular}{|l|c|c|c|}
\hline \multicolumn{1}{|c|}{ Variable } & Direct & Indirect & Total \\
\hline Specialization & 184.4448 & -48.9915 & 135.4534 \\
\hline Skill & -96.0001 & 25.4991 & -70.5009 \\
\hline Access*skill & 9.7355 & -2.5859 & 7.1496 \\
\hline
\end{tabular}

Based on the direct and indirect effects produced, it appears that specialization has a negative effect which means that specialization has a backwash effect. However, the opposite happened with the effect of the skill which had a spillover effect. This shows that specialization is not an absolute thing to continue to improve because it has risks, but skills also do not have a very negative effect given the potential spillover they have.

\section{Technology Effect}

Skills in using technology individually have a negative sign. This negative value indicates the inefficient use of technology in stimulating the performance of the export sector. But if it returns to describe the total effect of skills on exports, the total effect is obtained as follows. 


\section{Total effect Skills $=\beta_{2}+\beta_{3} *$ Access}

With the negative effects of skills in using technology on exports, it can be caused by the lack of available access. If you see the function above which is a decrease in functions 1 and 2, it can be said that the effect of the skill will also be affected by available access. If access is minimum, the existing skills will seem futile because they will not have a good container.

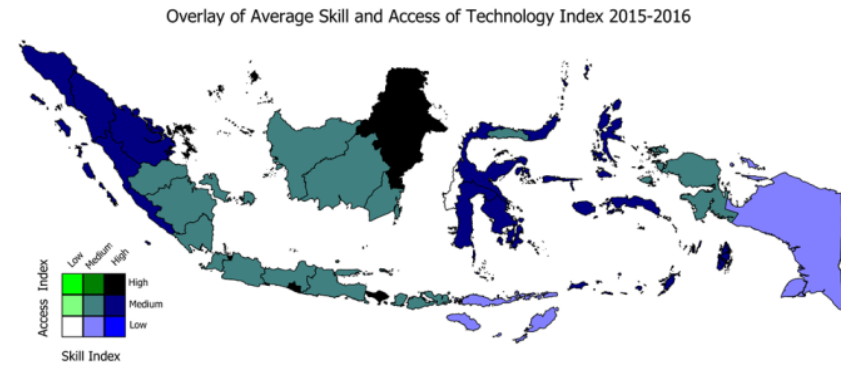

Fig. 1. Overlay of average skill and access index of technology in 20152016

Based on the mapping made regarding the overlay of access variables and skills in technological aspects, it was found that the dominant regions in Indonesia in 2015 to 2016 experienced a lack of access. Dominant regions have a high skill index but do not have adequate access indexes. This further strengthens the notion of the importance of access for Indonesia at present. In addition, access will provide optimal performance for skills in using technology, so that the performance of the export sector will be better.

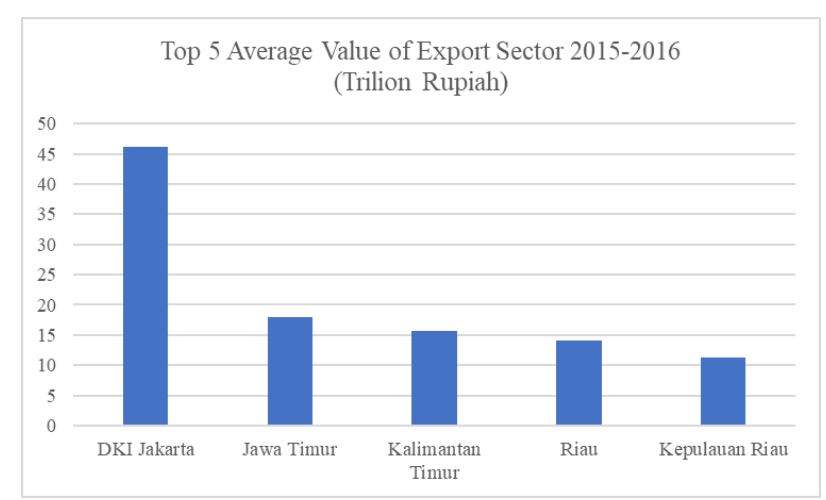

Fig. 2. Top 5 average value of export sector Indonesia
On the other hand, regions that have high access and skills have high export values. Seen from figure 2, DKI Jakarta, Kep. Riau and Kalimantan Timur have exports that are in the top 5 of Indonesia's exports. This supports the need for balancing of access and skills.

\section{CONCLUSION}

The conclusion that can be drawn from this research is how specialization has a good progressive effect in increasing the value of exports. In addition, spatial effects also appear that actually have a direction to compete with each other. This must be a government concern because in reality each region must be able to have a positive effect on each other

The use of technology will be able to produce positive effects if the available access is made easier and multiplied. This is indicated by the neutralizing effect given by access to the overall effect given by the skill in using technology.

There is good optimism from Indonesia because the progress of specialization and also the skill of using technology has a positive effect. This of course needs to be optimized again so that exports that are backed up can improve the economy will be more optimal.

\section{REFERENCES}

[1] P. A. P. Moran. Notes on continuous stochastic phenomena. Biometrika, 37:17-23, 1950 .

[2] Klinger, B. and Lederman, D. (2006). Diversification, innovation, and imitation inside the global technology frontier, World Bank Policy Research Working Paper No. 3872. Washington, DC: The World Bank

[3] Martin Robson (2006) Sectoral shifts, employment specialization and the efficiency of matching: An analysis using UK regional data, Regional Studies, 40:7, 743754, DOI: $10.1080 / 00343400600959371$

[4] Anselin L (1988) Spatial econometrics: Methods and models. Kluwer, Dordrecht

[5] www.bps.go.id

[6] Walpole, R. E., Myers, R. H., Myers, S. L., \& Ye, K. (2012). Probability \& statistics for engineers \& scientists (9th edition.). Boston: Prentice Hall.

[7] Fischer, M. M., Wang, J., 2011. Spatial Data Analysis: Models, Methods and Techniques. Springer, Berlin. 2, 2

[8] Cassey, Andrew J. (2015). Exporting Spatial Externalities. Washington: State University 